\title{
CRKII overexpression promotes the in vitro proliferation, migration and invasion potential of murine hepatocarcinoma Hca-P cells
}

\author{
ZANMEI ZHOU $^{1 *}$, XIUYAN SUN ${ }^{2 *}$, CHUNMEI GUO ${ }^{2}$, MING-ZHONG SUN ${ }^{3}$ and SHUQING LIU ${ }^{1}$ \\ ${ }^{1}$ Department of Biochemistry, Dalian Medical University, Dalian, Liaoning 116044; \\ ${ }^{2}$ Department of Laboratory Medicine, The Affiliated Hospital of Dalian University, Dalian, Liaoning 114012; \\ ${ }^{3}$ Department of Biotechnology, Dalian Medical University, Dalian, Liaoning 116044, P.R. China
}

Received May 13, 2018; Accepted January 11, 2019

DOI: $10.3892 / \mathrm{ol} .2019 .10194$

\begin{abstract}
Lymphatic metastasis is a major mechanism of tumor metastasis. The present study aimed to investigate the association of CRKII, a member of the CRK family, with the in vitro malignant behaviors of a murine hepatocarcinoma Hca-P cell line, with a lymph node metastatic rate of $\sim 25 \%$. Total mRNA was extracted from Hca-P cells, and then the murine CRKII gene was amplified by polymerase chain reaction and cloned into the pEASY-blunt cloning vector. Subsequently, the recombinant pcDNA3.1/V5-HisB-CRKII plasmid was constructed and transfected into Hca-P cells Western blotting indicated that the CRKII expression level in pcDNA3.1/V5-HisB-CRKII-Hca-P cells was increased by $\sim 185 \%$, compared with pcDNA3.1/V5-HisB-Hca-P cells. The stable overexpression of CRKII enhanced the in vitro proliferation ability, as measured with a Cell Counting Kit-8 assay, and the colony forming capacity was measured with a soft agar colony forming assay for Hca-P cells. The in vitro migration and invasion capacities of Hca-P cells were increased by $\sim 179$ and $156 \%$ in Hca-P cells, respectively, following the stable upregulation of CRKII. Collectively, the recombinant pcDNA3.1/V5-HisB-CRKII-Hca-P plasmid was constructed successfully. Additionally, the CRKII expression level was
\end{abstract}

Correspondence to: Professor Shuqing Liu, Department of Biochemistry, Dalian Medical University, 9 Western Section, Lvshun South Road, Dalian, Liaoning 116044, P.R. China

E-mail: 1sqsmz@163.com

Professor Ming-Zhong Sun, Department of Biotechnology, Dalian Medical University, 9 Western Section, Lvshun South Road, Dalian, Liaoning 116044, P.R. China

E-mail: smzlsq@163.com

${ }^{*}$ Contributed equally

Key words: CRKII, hepatocarcinoma, Hca-P, proliferation, invasion, migration positively associated with the in vitro proliferation, migration and invasion malignant properties of Hca-P cells.

\section{Introduction}

CRKII is a central signal adapter protein in signaling pathways that propagate extracellular activation from oncogenic tyrosine kinases to cellular targets $(1,2)$. CRKII contains a SH2 domain, which binds the focal adhesion components p130Cas and paxillin (3), growth factor receptors and signaling scaffold proteins (1) and two SH3 domains, which interacts with guanine nucleotide exchange factors, including DOCK180 (4) and C3G, to mediate the cell proliferation and adhesion by activating Rap1 and R-Ras $(3,5)$. Deregulation of CRK expression is associated a variety of cancer types, including lung cancer, breast cancer, glioblastoma and hepatocarcinoma (6-8). CRKII may be a potential tumor marker (9-11); however, the role and action mechanism of CRKII in tumor lymphatic metastasis are unclear.

As an early step of cancer malignancy (12), lymphatic metastasis is a major mechanism of tumor metastasis (13-17). A previous study demonstrated that lymph node metastasis (LNM) in cancer contributes to early metastasis detection and cancer progression $(9,12,13-17)$. The initial LNM of epithelial carcinoma commonly results in poor survival and prognosis of patients with cancer $(16,18)$. Hepatocarcinoma is one of the leading causes of cancer-associated mortalities globally due to its high recurrence, high metastasis and poor prognosis (19-21). Therefore, investigating the biological malignant ability and LNM potential of tumor cells improves the understanding of the progression of hepatocarcinoma.

Hca-P and Hca-F are two mouse hepatocarcinoma ascites cell lines sharing the same genetic background (15,22-24). Hca-F has a high LNM rate of $75 \%$ and Hca-P has a low LNM metastasis rate of $25 \%$. They metastasize only to lymph nodes, and do not disseminate to other organs (25). Hca-P cell is used as a low-LNM and LN-specific murine hepatocarcinoma cell model for the early discovery and diagnosis of tumor malignancies (15,22-25). Our previous study indicated that CRK is involved in the lymphatic metastatic potential of murine hepatocarcinoma cells $(22,23)$. CRKL, a member of the CRK adapter protein family, exhibited a tumor suppressor effect on the in vitro proliferation, migration 
and invasion, and in vivo tumor malignancy and LNM rate levels of Hca-P cells $(22,23)$. In the present study, the potential tumor promoter role of CRKII in hepatocarcinoma was investigated. By constructing the pcDNA3.1/V5-HisB-CRKII vector and CRKII-overexpressing Hca-P cells, the influence of the CRKII level on the in vitro proliferation, colony forming capacity, migration and invasion abilities of Hca-P cells was investigated.

\section{Materials and methods}

Cell culture. The murine hepatocarcinoma Hca-P cell line was created by the Department of Pathology, Dalian Medical University, and maintained in our laboratory at the Department of Biotechnology. During the 5-day experiment, Hca-P cells were administrated intraperitoneally, inoculated and purified in the abdominal cavities of 3 inbred Chinese 615-mice (male; age, 6 weeks; body weight, $20 \pm 2 \mathrm{~g}$ ) (24) that had been acclimatized for 5 days. The volume of ascites from three mice ranged from 0.9 to $1.2 \mathrm{ml}$ (4.5-6\% of body weght). The mice were supplied by the SPF Animal Laboratory Center of Dalian Medical University with ethical approval granted in March 2016. The 3 mice were placed in one cage, maintained at $23 \pm 0.5^{\circ} \mathrm{C}$ and $60-70 \%$ humidity with a 12 -h light/dark cycle (7:00 a.m.-7:00 p.m.) and allowed access to standard rodent chow and autoclaved filtered water ad libitum. For euthanasia, each mouse was injected with ketamine (Sigma-Aldrich; Merck $\mathrm{KGaA}$, Darmstadt, Germany) at $100 \mathrm{mg} / \mathrm{kg}$ and with xylazine (Sigma-Aldrich; Merck $\mathrm{KGaA}$ ) at $10 \mathrm{mg} / \mathrm{kg}$ according to a previous study (26) and our experience. Mice were sacrificed in a tank with $20 \%$ volume displacement per minute by $\mathrm{CO}_{2}$ flow, followed by cervical dislocation to confirm death. The purified Hca-P cells were then cultured in 85\% RPMI-1640 medium (Gibco; Thermo Fisher Scientific, Inc., Waltham, MA, USA) supplemented with $15 \%$ fetal bovine serum (PAA Laboratories GmbH; GE Healthcare Life Sciences, Little Chalfont, $\mathrm{UK}$ ) at $37^{\circ} \mathrm{C}$ in a humidified incubator with $5 \% \mathrm{CO}_{2}$.

Polymerase chain reaction (PCR) amplification. According to gene sequence (GenBank: NM_133656), the forward (F) and reverse (R) primers of CRKII were designed by Oligo7 as F: 5'-CCAAGCTTACAATGGCGGGCAACTTCGACTC-3'; and R: 5'-CGGGATCCATTGCTGAAGTCCTCATCGG-3'. The F primer contains a HindIII restriction cleavage site and $\mathrm{R}$ primer contains a BamHI restriction cleavage site. Total RNA was extracted from Hca-P cells using TRIzol ${ }^{\circledR}$ reagent (Thermo Fisher Scientific, Inc.), according to the manufacturer's protocol, and reverse transcription was conducted with a RNA PCR kit Ver.3.0 (Takara Bio, Inc., Otsu, Japan). Using PrimerScript RTase and PrimeSTAR HS DNA Polymerase (Takara Bio, Inc.), semi-quantitative PCR was performed on a MyCycle $^{\mathrm{TM}}$ Thermal Cycler (Bio-Rad Laboratories, Inc., Hercules, CA, USA). The reaction was performed initially at $98^{\circ} \mathrm{C}$ for $2 \mathrm{~min}$, then amplified for 35 cycles using the following conditions: $98^{\circ} \mathrm{C}$ for $10 \mathrm{sec}, 65^{\circ} \mathrm{C}$ for $15 \mathrm{sec}$ and $72^{\circ} \mathrm{C}$ for $1 \mathrm{~min}$, and finally maintained at $72^{\circ} \mathrm{C}$ for $5 \mathrm{~min}$. The PCR products were analyzed by $1 \%$ agarose gel electrophoresis containing $2.5 \%(\mathrm{v} / \mathrm{v})$ ethidium bromide.

Construction of pEASY-blunt simple-CRKII cloning vector. The specific gel band of PCR product for CRKII from the aforementioned protocol was sliced and purified with an Universal DNA Purification kit (Tiangen Biotech Co., Ltd., Beijing, China). The purified PCR DNA product containing HindIII and BamHI sites was hydrolyzed by HindIII and BamHI enzymes, then ligated into a pEASY-blunt simple cloning vector (Transgen Biotech Co., Ltd., Beijing, China). The ligated product was transformed into E. coli Novablue and screened by blue-white screening. Positive recombinant plasmid was extracted with the alkaline-lysis method (27), digested by HindIII/BamHI, analyzed by $1 \%$ agarose gel electrophoresis and the DNA was sequenced.

Construction of pcDNA3.1/V5-HisB-CRKII plasmid. The pEASY-blunt simple cloning vector containing CRKII was digested with HindIII and BamHI. The cleaved insert was ligated into a pcDNA3.1/V5-HisB vector (Shanghai CPG Biotech Co., Ltd., Shanghai, China) with T4 DNA ligase (Takara Bio, Inc.) at $16^{\circ} \mathrm{C}$ overnight. Subsequently, the ligation mixture was transformed into competent $E$. coli Novablue and amplified for plasmid extraction with an EZNA ${ }^{\circledR}$ Endo-Free plasmid mini kit (Omega Bio-Tek, Inc., Norcross, GA, USA). Finally, the plasmid extraction was measured with a Thermo Scientific NanoDrop 2000 (Thermo Fisher Scientific, Inc.) and stored at $-20^{\circ} \mathrm{C}$ for further study.

CRKII transfection. Hca-P cells were seeded at the density of $1 \times 10^{5}$ cells $/ 500 \mu 1$ in a 24 -well plate. Each extracted plasmid was mixed with Lipofectamine ${ }^{\circledR} 2000$ (Invitrogen; Thermo Fisher Scientific, Inc.) at a dilution of $1.5 \mu \mathrm{g} / 4.5 \mu \mathrm{l}$ and mixed with RPMI-1640 medium to a final volume of $100 \mu \mathrm{l}$ for $20 \mathrm{~min}$. The plasmid mixtures was separately added into each well containing Hca-P cells, mixed well and transfected for $24 \mathrm{~h}$ at $37^{\circ} \mathrm{C}$ with $5 \% \mathrm{CO}_{2}$. CRKII expression and upregulation level in pcDNA3.1/V5-HisB-CRKII-Hca-P was determined by western blotting and compared with pcDNA3.1/V5-HisB-Hca-P cells. Experiments were performed $24 \mathrm{~h}$ subsequent to transfection.

SDS-PAGE and western blotting. Protein samples were extracted from the cell pellets of pcDNA3.1/V5-HisBCRKII-Hca-P and pcDNA3.1/V5-HisB-Hca-P by ultrasound sonication in $1 \mathrm{ml}$ ice-cold lysis buffer (Nanjing KeyGen Biotech Co., Ltd., Nanjing China) supplemented with $1 \mu 1100$ mmol/1 phenylmethylsulfonyl fluoride, $2 \mu 1$ phosphatase inhibitors and $0.2 \mu \mathrm{l}$ protease inhibitor. Supernatants were collected by centrifugation at $12,879 \times \mathrm{g}$ for $15 \mathrm{~min}$ at $4^{\circ} \mathrm{C}$. Protein concentration was determined using the Bradford method. Equal amount of protein samples $(20 \mu \mathrm{g})$ from each group were separated by $12 \%$ SDS-PAGE. Protein bands were then transferred onto a nitrocellulose membrane (EMD Millipore, Billerica, MA, USA), blocked with 5\% (w/v) skimmed milk for $2 \mathrm{~h}$ at room temperature, and incubated with CRKII (1:1,000; sc-9004; Santa Cruz Biotechnology, Inc., Dallas, TX, USA) and GAPDH (1:5,000; 1049-1-AP; Proteintech Group, Inc., Chicago, IL, USA) antibodies rotating at $100 \mathrm{rpm}$ using an orbital shaker at $4^{\circ} \mathrm{C}$ overnight. After washing with TBS with $0.5 \%(\mathrm{v} / \mathrm{v})$ Tween-20 buffer for three times for $10 \mathrm{~min}$ each, the NC membrane was incubated with peroxidase-conjugated goat anti-rabbit/anti-mouse (1:5,000; TA130001/TA130015; OriGene Technologies, Inc., Beijing, China) for $2 \mathrm{~h}$ at room temperature. Immunoreactive proteins bands were visualized 
by enhanced chemiluminescent WesternBright ${ }^{\mathrm{TM}}$ ECL substrate (K-12045-D50; Adavansta; VWR, Radnor, PA, USA) and detected by Bio-Rad ChemiDoc ${ }^{\mathrm{TM}}$ MP imaging system (Bio-Rad Laboratories, Inc.) and analyzed by densitometric analysis using the Image Lab Software 4.0.1 (Bio-Rad Laboratories, Inc.).

Cell Counting Kit-8 (CCK-8) assay for cell proliferation. The effect of CRKII overexpression on Hca-P proliferation was measured using CCK-8 (Takara Bio, Inc.). The transfected pcDNA3.1/V5-HisB-CRKII-Hca-P and pcDNA3.1/V5-HisB-Hca-P cells were seeded into a 96-well plate with the density of 1,500 cells/well in $100 \mu$ l RPMI-1640 medium with $15 \% \mathrm{FBS}$ at $37^{\circ} \mathrm{C}$. The relative cell viabilities were detected using a CCK- 8 assay at the time intervals 24, 48, 72 and $96 \mathrm{~h}$. A total of $10 \mu \mathrm{l} \mathrm{CCK}-8$ solution was added into each well and continuously incubated at $37^{\circ} \mathrm{C}$ for $1.5 \mathrm{~h}$. The absorbance at $450 \mathrm{~nm}$ was recorded to calculate the relative cell numbers.

Soft-agar colony forming assay. The effect of CRKII overexpression on the anchorage-independent growth of Hca-P cells was investigated. The 6 -well plates were coated with two-layer soft agars. Soft agars (Amresco, LLC, Solon, OH, USA) of $1.2 \%(\mathrm{w} / \mathrm{v})$ and $0.7 \%(\mathrm{w} / \mathrm{v})$ were completely melted by autoclaving and kept in a $50^{\circ} \mathrm{C}$ incubator. For the base layer, the $1.2 \%$ soft agar was mixed with equal volume of $2 \mathrm{X}$ medium (85\% RPMI-1640/15\% FBS), quickly added into a 6-well plate at $2.0 \mathrm{ml} \mathrm{mixture/well} \mathrm{and} \mathrm{cooled} \mathrm{to} \mathrm{room} \mathrm{temperature.}$ Subsequently, the mixture of $0.7 \%$ soft agar solution and $2 \mathrm{X}$ medium (85\% RPMI-1640/15\% FBS; 1:1) with $1 \times 10^{3}$ cells of each group was pooled immediately onto the base layer, as the upper layer. The plates were kept at $37^{\circ} \mathrm{C}$ with $5 \% \mathrm{CO}_{2}$ for 10-14 days until visible cell colonies appeared. Following this, the cells were stained with crystal violet $(0.05 \%)$ for $40 \mathrm{~min}$ at room temperature and extensively washed with PBS buffer for 3-5 min. The colonies were imaged using a Canon IXUS $115 \mathrm{HS}$ digital camera (12 megapixels; Canon, Inc., Tokyo, Japan) fixed $\sim 15 \mathrm{~cm}$ above the wells and focused on the whole view of each well. The imaged colonies were then counted using Photoshop CS3 software (Adobe Systems Europe, Ltd., Maidenhead, UK) with the aid of the number counting function.

Boyden transwell chamber assay for cell migration and invasion. Corning Costar Transwell cell culture inserts (Corning Inc., Corning, NY, USA) were employed to investigate the effect of ANXA5 overexpression on the in vitro migration and invasion properties of Hca-P cells. For the migration assay, $600 \mu 1$ RPMI-1640 with $20 \%$ FBS was loaded into each lower chamber. A total of 10,000 cells from each group were separately loaded into one upper chamber in $200 \mu \mathrm{l}$ RPMI-1640 medium and incubated at $37^{\circ} \mathrm{C}$ with $5 \% \mathrm{CO}_{2}$ for $24 \mathrm{~h}$. The non-migrated cells on the upper surface of the insert were carefully wiped off using cotton swabs. The cells that had migrated to the lower surface of the filter were fixed in methanol (Sigma-Aldrich; Merck KGaA) for $30 \mathrm{~min}$, dried for $5 \mathrm{~min}$ at room temperature, stained in $0.1 \%$ crystal violet for 40 min, washed with PBS $(200 \mu 1)$ and counted by randomly selecting 5 fields per well with a BX63 upright light microscope (Olympus Corporation, Tokyo, Japan) at a magnification of $\mathrm{x} 200$. For the invasion assay, the Transwell surface was coated with $50 \mu 1$ ice-cold ECM gel $(2 \mathrm{mg} / \mathrm{ml}$; Sigma-Aldrich; Merck KGaA) and incubated at $37^{\circ} \mathrm{C}$ for $6 \mathrm{~h}$. Subsequently, the Transwells were dried at room temperature for $30 \mathrm{~min}$, and then hydrated with $50 \mu 1$ serum-free RPMI-1640. RPMI-1640 $(600 \mu \mathrm{l})$ with $20 \%$ FBS was then added into the lower chamber. Next, 7,500 cells suspended in $150 \mu$ l RPMI-1640 from each group were loaded into the upper chamber. The rest of the steps were the same as those described for the migration assay.

Statistical analysis. Data are represented as the mean \pm standard deviation of at least three independent experiments. Differences between groups were determined by paired Student's t-test analysis. $\mathrm{P}<0.05$ was considered to indicate a statistically significant difference. All statistical analyses were performed using SPSSx17.0 software (SPSS, Inc., Chicago, IL, USA).

\section{Results}

Gene cloning and pcDNA3.1/V5-HisB-CRKII plasmid construction. As depicted in Fig. 1A, the CRKII cloning vector was successfully constructed. The expected size of bands for the pEASY-blunt simple vector and CRKII following digestion with HindIII and BamHI were 3,830 and 923 bp, as appeared in lane 4. A band of 4,763 bp was expected following digestion with BamHI or HindIII alone (lanes 2 and 3). Subsequently, the pcDNA3.1/V5-HisB-CRKII expression plasmid was established by inserting the digested fragment from the CRKII cloning vector into the pcDNA3.1/V5-HisB expression vector. The pcDNA3.1/V5-HisB vector is $\sim 5,500 \mathrm{bp}$. As shown in Fig. 1B, the band with size of $\sim 6,200$ bp by BamHI cleavage alone or by HindIII cleavage indicated that CRKII was inserted into the pcDNA3.1/V5-HisB vector. The bands with sizes of $\sim 5,200$ and 920 bp on the gel following digestions with BamHI and HindIII were the expected sizes for the pcDNA3.1/V5-HisB vector and CRKII. The DNA sequencing results of the cloning and expression vectors confirmed CRKII insertion (data not shown). These results indicated that the pcDNA3.1/V5-HisB-CRKII plasmid was successfully constructed.

CRKII is stably upregulated in Hca-P cells. Western blotting indicated in Fig. 2A that the CRKII expression level was upregulated in pcDNA3.1/V5-HisB-CRKII-Hca-P cells. Compared with pcDNA3.1/V5-HisB-Hca-P, CRKII protein level in pcDNA3.1/V5-HisB-CRKII-Hca-P cells was significantly increased by $\sim 185 \%$ ( $<<0.001$; Fig. 2B). Successful overexpression of CRKII makes it feasible to investigate its protein level change on the biological properties of Hca-P cells.

CRKII upregulation enhances the in vitro proliferation of Hca-P cells. The impact of CRKII overexpression on the in vitro proliferation of Hca-P was accessed with a CCK-8 assay. As depicted in Fig. 3A, the proliferation of pcDNA3.1/V5-HisB-CRKII -Hca-P cells was significantly increased following CRKII overexpression, compared with that in pcDNA3.1/V5-HisB-Hca-P cells. The relative proliferation rates of pcDNA3.1/V5-HisB-CRKII-Hca-P cells at the time intervals of 72 and $96 \mathrm{~h}$ were 246 and $150 \%$ increased, compared with those in pcDNA3.1/V5-HisB-Hca-P cells; these differences were statistically significant (Fig. 3A). The aforementioned results indicate that the CRKII level is positively associated with the in vitro proliferation of Hca-P cells. 
A

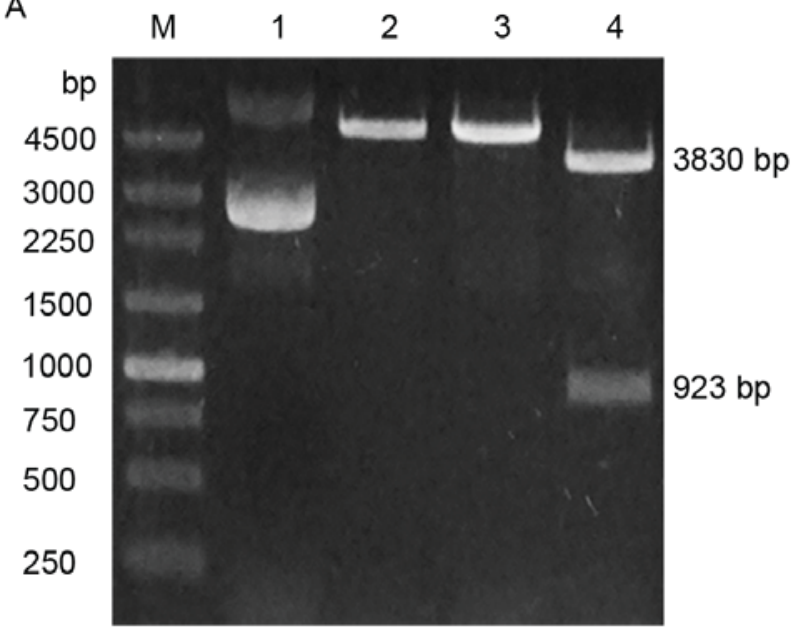

B

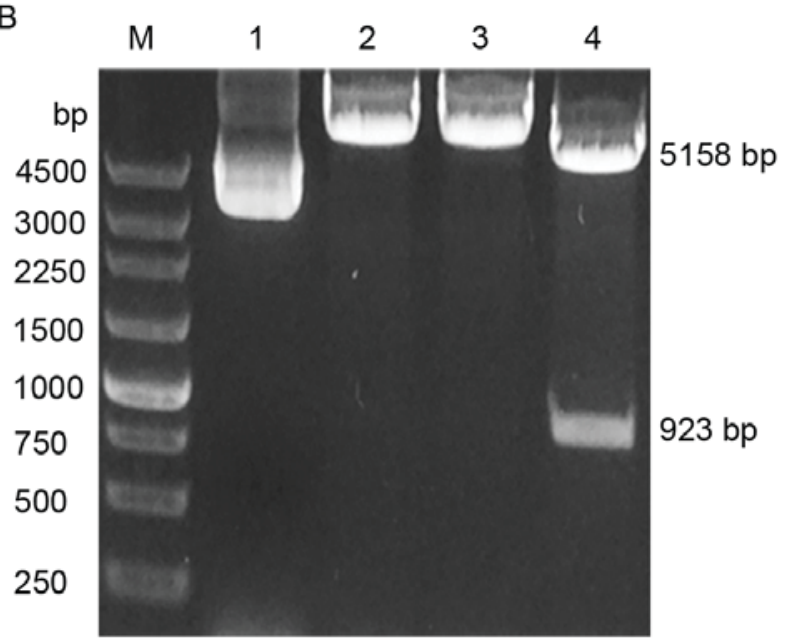

Figure 1. Agarose gel electrophoresis of cloning and expression vectors of CRKII. (A) pEASY-CRKII cloning vector. (B) pcDNA3.1/V5-HisB-CRKII expression vector. M, marker; 1, vector; 2, products of vector digested with BamHI; 3, products of vector digested with HindIII 4, products of vector digested with BamHI and HindIII.

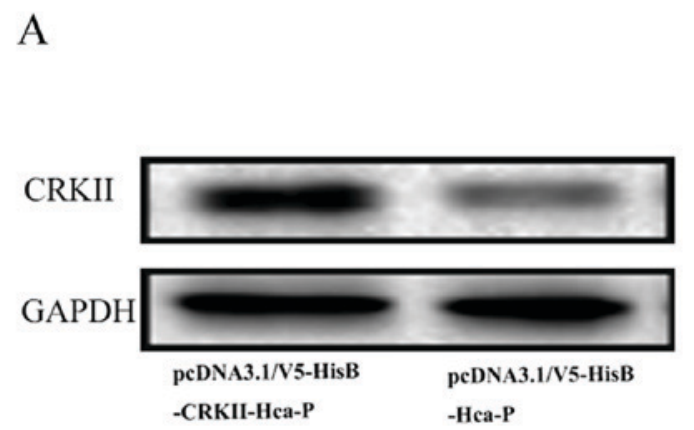

$\mathrm{B}$

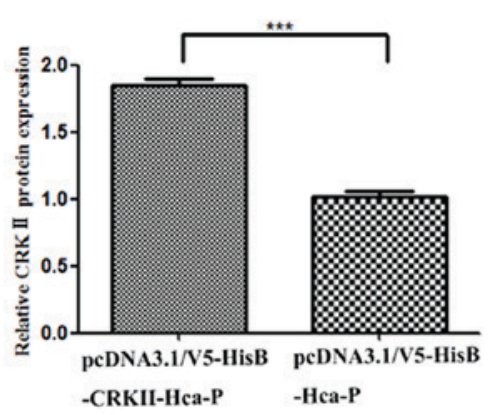

Figure 2. CRKII overexpression in Hca-P cells. (A) Western blot of CRKII in pcDNA3.1/V5-HisB-Hca-P and pcDNA3.1/V5-HisB-CRKII-Hca-P cells. (B) Relative expression levels of CRKII in pcDNA3.1/V5-HisB-Hca-P and pcDNA3.1/V5-HisB-CRKII- Hca-P cells. CRKII was significantly increased in pcDNA3.1/V5-HisB-CRKII-Hca-P cells, compared with pcDNA3.1/V5-HisB-Hca-P cells, ${ }^{* * *} \mathrm{P}<0.001$.

CRKII upregulation enhances the colony forming ability of Hca-P. The CRKII level increase enhances the colony forming capacity of Hca-P cells. The number of colonies formed in soft agar was $184 \pm 12$ for Hca-P cells transfected with pcDNA3.1/V5-HisB-CRKII, and $68 \pm 8$ for Hca-P cells transfected with pcDNA3.1/V5-HisB (Fig. 3B). The relative colony forming percentages were $18.4 \pm 1.2$ and $6.8 \pm 0.8 \%$, respectively. The colony forming capacity of Hca-P cells increased by $\sim 171.0 \%$ following CRKII overexpression. Consistent with its promotion of Hca-P proliferation, CRKII upregulation increased the colony forming activity, indicating CRKII is a promoter of Hca-P malignant potential.

CRKII upregulation promotes migration and invasion capacities of Hca-P. Transwell chamber assays indicated that increased CRKII expression significantly enhanced the in vitro migration and invasion capacities of Hca-P cells (Fig. 4).

The numbers of migrated pcDNA3.1/V5-HisBCRKII-Hca-P and pcDNA3.1/V5-HisB-Hca-P cells were measured as $39.7 \pm 0.8$ and $14.2 \pm 0.3$ per field (Fig. $4 \mathrm{~A}$ ). The migration capacity of pcDNA3.1/V5-HisB-CRKII-Hca-P cells was 2.8 -fold increased, compared with pcDNA3.1/V5-HisB-
Hca-P cells (Fig. 4A). Therefore, CRKII overexpression significantly increases Hca-P migration.

The invasion ability of Hca-P cells was increased significantly following CRKII overexpression (Fig. 4B). The invaded numbers of pcDNA3.1/V5-HisB-CRKII-Hca-P and pcDNA3.1/V5-HisB-Hca-P cells were measured as $43.4 \pm 0.5$ and $16.9 \pm 0.5$ per field (Fig. 4B). The in vitro invasion capacity of pcDNA3.1/V5-HisB-CRKII-Hca-P cells was 2.6-fold of that of pcDNA3.1/V5-HisB-Hca-P cells (Fig. 4B). Therefore, CRKII overexpression results in significantly increased invasion potential of Hca-P.

\section{Discussion}

The overexpression of CRKII was associated with the development and progression of lung tumors (6), glioblastoma (7), oral squamous cell carcinoma (28), pancreatic ductal adenocarcinoma (29) and salivary gland tumors (30). However, there is limited knowledge regarding the role of CRKII in hepatocarcinoma. Results from our previous study (31) indicated that CRK family proteins are potentially involved in the lymphatic metastais of hepatocarcinoma by comparative proteomics using Hca-P and Hca-F, two murine hepatocarcinoma ascites syngeneic 
A

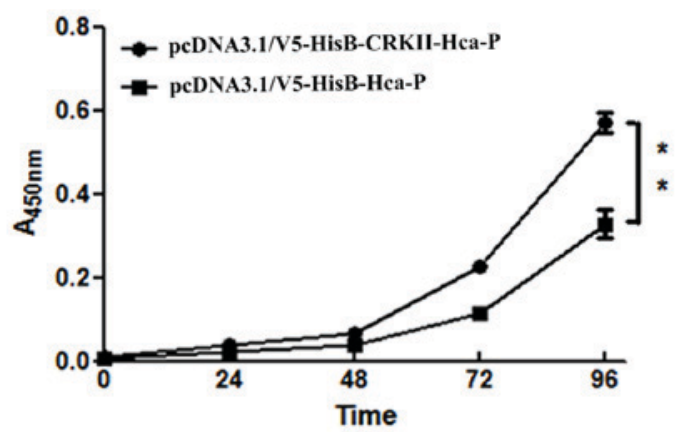

B

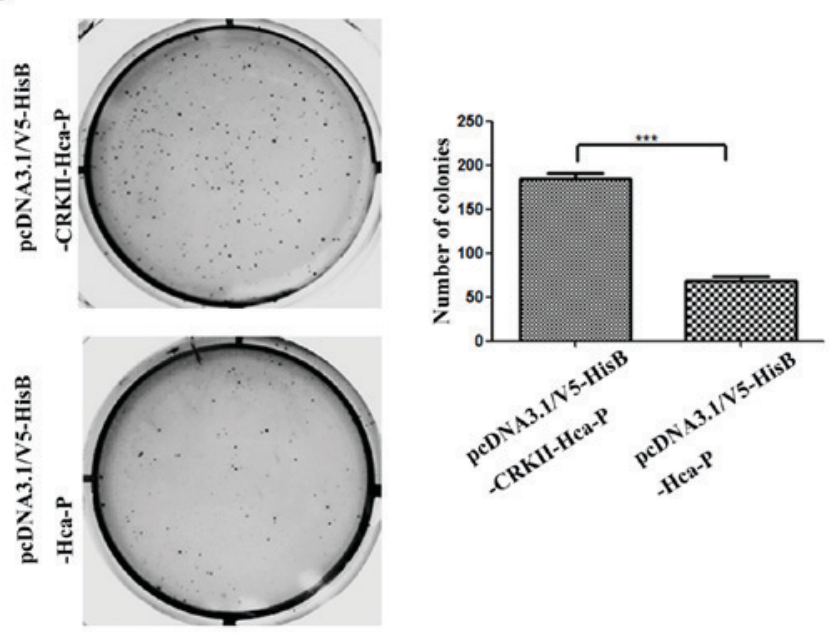

Figure 3. CRKII affects the proliferation and colony forming capacities of Hca-P. (A) CRKII upregulation enhances Hca-P proliferation. (B) CRKII overexpression enhances Hca-P colony forming capacity. The relative capacity was compared between pcDNA3.1/V5-HisB-CRKII-Hca-P and pcDNA3.1/V5-HisB-Hca-P cells. ${ }^{* * *} \mathrm{P}<0.01$ and ${ }^{* * *} \mathrm{P}<0.001$.

cell lines with low and high LNM rates, respectively (24). It was determined that another member of CRK family, CRKL, exhibited a tumor suppressor effect on the in vitro proliferation, migration and invasion, and in vivo tumor malignancy and LNM rate levels of Hca-P cells $(22,23)$. Therefore, in the present study, the role of CRKII in Hca-P malignant properties were investigated by elevating its expression level in Hca-P cells.

CRKII level affects the in vitro proliferation of Hca-P cells. It was reported that the CRKII level is positively correlated with the proliferation of glioblastoma KMG4 (7) and pancreatic ductal adenocarcinoma cell lines (29). Consistently, the present study demonstrated that CRKII overexpression significantly promoted the proliferation (Fig. 3A) and colony forming capacity of Hca-P cells (Fig. 3B).

It was reported that CRKII mediates cell metastasis and invasion via p130Cas, paxillin and Dock180 $(32,33)$. CRKI/II knockdown inhibits the migration and invasion of human cancer cell lines MDA-231, MDA-435s, H1299, KB and HeLa (10). Additionally, CRKII overexpression increases the migration and invasiveness of oral squamous cell carcinoma (28). Consistently, the present study indicated that overexpression of CRKII significantly increased the migration and invasion capacities of Hca-P cells by $\sim 179 \%$ (Fig. 4A) and $\sim 156 \%$ (Fig. $4 \mathrm{~B}$ ), respectively. CRKII expression level is positively associated with the migration and invasion of Hca-P
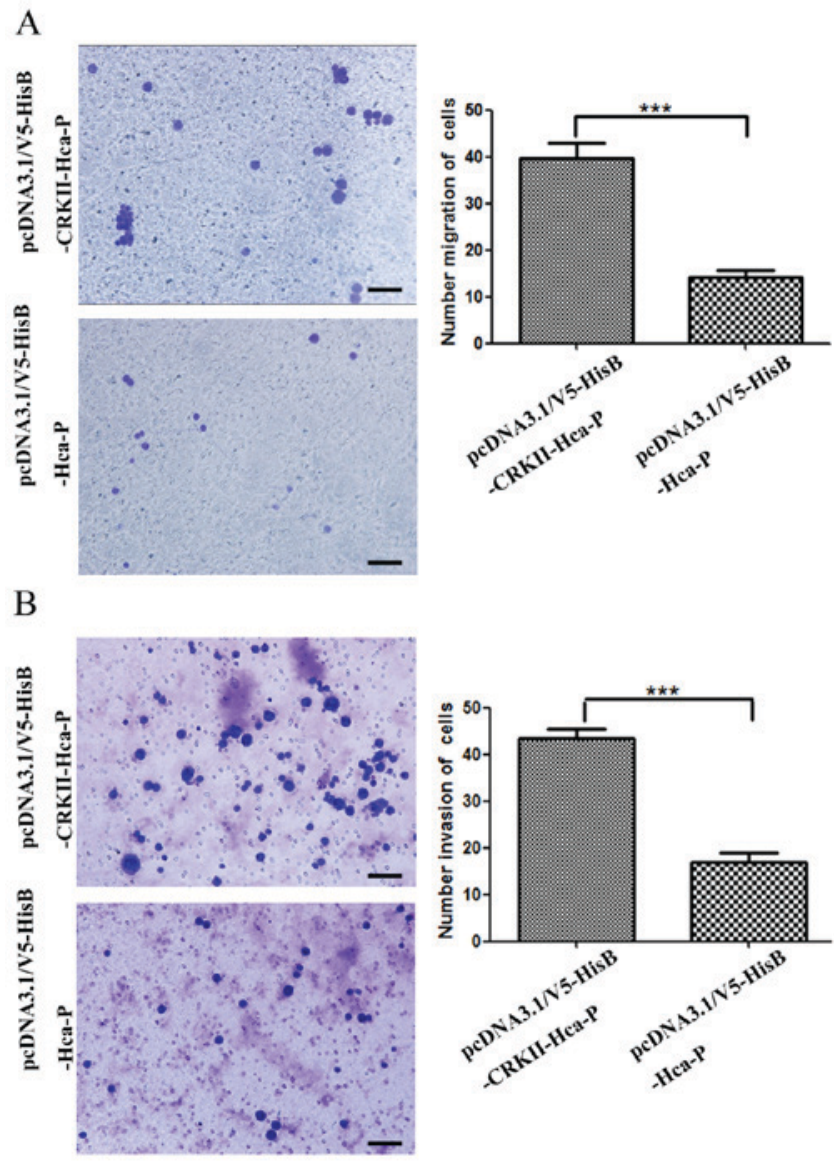

Figure 4. CRKII overexpression promotes the migration and invasion of Hca-P. (A) CRKII overexpression promotes the in vito migration ability of Hca-P. (B) CRKII overexpression promotes the in vito invasion ability of Hca-P. Images of migrated and invaded cells were photographed using a microscope at x200 magnification. ${ }^{* * *} \mathrm{P}<0.001$.

cells. The expression level change of CRKII does not affect the expression levels of p130Cas and Dock180 (data not shown); while notably, the expression changes of CRKI and CRKL induced the levels of p130Cas and Dock180 (unpublished data). Therefore, the detailed mechanism of CRKII action in tumorigenesis deserves further investigation.

In conclusion, CRKII expression level was positively associated with the in vitro proliferation, migration and invasion properties of Hca-P cells. The present study demonstrates the association of CRKII with the malignant behaviors of hepatocarcinoma cells and lymphatic metastasis mechanism of hepatocarcinoma.

\section{Acknowledgements}

The authors would like to thank Professor Jianwu Tang (Department of Pathology, Dalian Medical University, Dalian, China) for providing the Hca-P cell line.

\section{Funding}

This study was supported by grants from the National Natural Science Foundation of China (nos. 81672737, 81272186 and 81171957 ) and the Provincial Natural Science Foundation of Liaoning (nos. 2015020266 and 2014023047). 


\section{Availability of data and materials}

All data used and analyzed in current study are available from corresponding authors on reasonable request.

\section{Authors' contributions}

$\mathrm{ZZ}$ and XS performed the experiments and wrote the draft. CG contributed in data analysis. MS and SL designed and supervised the study, and corrected the manuscript.

\section{Ethics approval}

The current study was approved by the Ethical Committee of Dalian Medical University (Permit Number: L20160029).

\section{Patient consent for publication}

No applicable.

\section{Competing interests}

The authors declare that they have no competing interests.

\section{References}

1. Feller SM: Crk family adaptors-signalling complex formation and biological roles. Oncogene 20: 6348-6371, 2001.

2. Birge RB, Kalodimos C, Inagaki F and Tanaka S: Crk and CrkL adaptor proteins: Networks for physiological and pathological signaling. Cell Commun Signal 7: 13, 2009.

3. Bos JL, Rehmann H and Wittinghofer A: GEFs and GAPs: Critical elements in the control of small G proteins. Cell 129. 865-877, 2007.

4. Hasegawa H, Kiyokawa E, Tanaka S, Nagashima K, Gotoh N, Shibuya M, Kurata T and Matsuda M: DOCK180, a major CRK-binding protein, alters cell morphology upon translocation to the cell membrane. Mol Cell Biol 16: 1770-1776, 1996.

5. Tanaka S, Morishita T, Hashimoto Y, Hattori S, Nakamura S, Shibuya M, Matuoka K, Takenawa T, Kurata T, Nagashima K, et al C3G, a guanine nucleotide-releasing protein expressed ubiquitously, binds to the Src homology 3 domains of CRK and GRB2/ASH proteins. Proc Natl Acad Sci USA 91: 3443-3447, 1994.

6. Miller CT, Chen G, Gharib TG, Wang H, Thomas DG, Misek DE, Giordano TJ, Yee J, Orringer MB, Hanash SM and Beer DG: Increased C-CRK proto-oncogene expression is associated with an aggressive phenotype in lung adenocarcinomas. Oncogene 22: 7950-7957, 2003.

7. Wang L, Tabu K, Kimura T, Tsuda M, Linghu H, Tanino M, Kaneko S, Nishihara $\mathrm{H}$ and Tanaka S: Signaling adaptor protein Crk is indispensable for malignant feature of glioblastoma cell line KMG4. Biochem Biophys Res Commun 362: 976-981, 2007.

8. Sriram $\mathrm{G}$ and Birge RB: Emerging roles for crk in human cancer. Genes Cancer 1: 1132-1139, 2010.

9. Fathers KE, Bell ES, Rajadurai CV, Cory S, Zhao H, Mourskaia A, Zuo D, Madore J, Monast A, Mes-Masson AM, et al: Crk adaptor proteins act as key signaling integrators for breast tumorigenesis. Breast Cancer Res 14: R74, 2012.

10. Rodrigues SP, Fathers KE, Chan G, Zuo D, Halwani F, Meterissian S and Park M: CrkI and CrkII function as key signaling integrators for migration and invasion of cancer cells. Mol Cancer Res 3: 183-194, 2005.

11. Bell ES and Park M: Models of crk adaptor proteins in cancer. Genes Cancer 3: 341-352, 2012.

12. Guo Y, Li S, Qu J, Wang S, Dang Y, Fan J, Yu S and Zhang J: MiR-34a inhibits lymphatic metastasis potential of mouse hepatoma cells. Mol Cell Biochem 354: 275-282, 2011.

13. Huang Y, Wang Q, Du Y, Bai L, Jin F, Zhang J, Fan S, Wang H, Song L, Gao Y, et al: Inhibition of annexin A7 gene and protein induces the apotosis and decreases the invasion, migration of the hepatocarcinoma cell line. Biomed Pharmacother 68: 819-824, 2014.
14. Zhang YH, Wang SQ, Sun CR, Wang M, Wang B and Tang JW: Inhibition of JNK1 expression decreases migration and invasion of mouse hepatocellular carcinoma cell line in vitro. Med Oncol 28: 966-972, 2011.

15. Wu J, Meng J, Du Y, Huang Y, Jin Y, Zhang J, Wang B, Zhang Y, Sun M and Tang J: RACK1 promotes the proliferation, migration and invasion capacity of mouse hepatocellular carcinoma cell line in vitro probably by $\mathrm{PI} 3 \mathrm{~K} / \mathrm{Racl}$ signaling pathway. Biomed Pharmacother 67: 313-319, 2013.

16. Sleeman JP: The lymph node as a bridgehead in the metastatic dissemination of tumors. Recent Results Cancer Res 157: 55-81, 2000.

17. Kawada K and Taketo MM: Significance and mechanism of lymph node metastasis in cancer progression. Cancer Res 71: 1214-1218, 2011.

18. Kabilova TO, Kovtonyuk LV, Zonov EV, Ryabchikova EI, Popova NA, Nikolin VP, Kaledin VI, Zenkova MA, Vlassov VV and Chernolovskaya EL: Immunotherapy of hepatocellular carcinoma with small double-stranded RNA. BMC Cancer 14: $338,2014$.

19. Abdel-Rahman O: Revisiting oxaliplatin-based regimens for advanced hepatocellular carcinoma. Curr Oncol Rep 16: 394, 2014.

20. Quetglas IM, Moeini A, Pinyol R and Llovet JM: Integration of genomic information in the clinical management of HCC. Best Pract Res Clin Gastroenterol 28: 831-842, 2014.

21. Chuang SC, La Vecchia C and Boffetta P: Liver cancer: Descriptive epidemiology and risk factors other than HBV and HCV infection. Cancer Lett 286: 9-14, 2009.

22. Shi J, Meng L, Sun MZ, Guo C, Sun X, Lin Q and Liu S: CRKL knockdown promotes in vitro proliferation, migration and invasion, in vivo tumor malignancy and lymph node metastasis of murine hepatocarcinoma Hca-P cells. Biomed Pharmacother 71: 84-90, 2015.

23. Lin Q, Sun MZ, Guo C, Shi J, Chen X and Liu S: CRKL overexpression suppresses in vitro proliferation, invasion and migration of murine hepatocarcinoma Hca-P cells. Biomed Pharmacother 69: 11-17, 2015.

24. Liu S, Guo C, Wang J, Wang B, Qi H and Sun MZ: ANXA11 regulates the tumorigenesis, lymph node metastasis and 5-fluorouracil sensitivity of murine hepatocarcinoma Hca-P cells by targeting c-Jun. Oncotarget 7: 16297-16310, 2016.

25. Hou L, Li Y, Jia YH, Wang B, Xin Y, Ling MY and Lü S: Molecular mechanism about lymphogenous metastasis of hepatocarcinoma cells in mice. World J Gastroenterol 7: 532-536, 2001.

26. Levin-Arama M, Abraham L, Waner T, Harmelin A, Steinberg DM, Lahav T and Harlev M: Subcutaneous compared with intraperitoneal KetamineXylazine for anesthesia of mice. J Am Assoc Lab Anin Sci 55: 794-800, 2016.

27. Feliciello I and Chinali G: A modified alkaline lysis method for the preparation of highly purified plasmid DNA from Escherichia coli. Anal Biochem 212: 394-401, 1993.

28. Yamada S, Yanamoto S, Kawasaki G, Rokutanda S, Yonezawa H, Kawakita A and Nemoto TK: Overexpression of CRKII increases migration and invasive potential in oral squamous cell carcinoma. Cancer Lett 303: 84-91, 2011.

29. Liu R, Wang Q, Xu G, Li K, Zhou L and Xu B: The adaptor protein CrkII regulates IGF-1-induced biological behaviors of pancreatic ductal adenocarcinoma. Tumour Biol 37: 817-822, 2016.

30. Askari M, Darabi M, Jahanzad E, Mostakhdemian Hosseini Z, Musavi Chavoshi $M$ and Darabi M: Immunohistochemichal assessment of the CrkII proto-oncogene expression in common malignant salivary gland tumors and pleomorphic adenoma. J Dent Res Dent Clin Dent Prospects 9: 29-34, 2015.

31. Sun MZ, Liu S, Tang J, Wang Z, Gong X, Sun C and Greenaway F: Proteomics analysis of two mice hepatocarcinoma ascites syngeneic cell lines with high and low lymph node metastasis rates provide potential protein markers for tumor malignancy attributes to lymphatic metastasis. Proteomics 9: 3285-3302, 2009.

32. Klemke RL, Leng J, Molander R, Brooks PC, Vuori K and Cheresh DA: CAS/Crk coupling serves as a 'molecular switch' for induction of cell migration. J Cell Biol 140: 961-972, 1998.

33. Kiyokawa E, Hashimoto Y, Kurata T, Sugimura H and Matsuda M: Evidence that DOCK180 up-regulates signals from the CrkII-p130(Cas) complex. J Biol Chem 273: 24479-24484, 1998. 